\title{
STUDI KOMPARATIF FAKTOR KESUKSESAN DALAM MERANCANG ARSITEKTUR BANGUNAN UNTUK MENINGKATKAN KEBERHASILAN IMPLEMENTASI TEKNOLOGI INFORMASI
}

\author{
Wibowo Kosasih", Dyah Budiastuti², Bahtiar Saleh Abbas ${ }^{3}$, Adler Haymans Manurung ${ }^{4}$ \\ ${ }^{1}$ Management Department, BINUS Business School Doctor of Research in Management, Bina Nusantara University, Jakarta \\ Email:wibowo@binus.ac.id \\ ${ }^{2}$ Management Department, BINUS Business School Doctor of Research in Management, Bina Nusantara University, Jakarta \\ Email: dbudiastuti@binus.edu \\ ${ }^{3}$ Management Department, BINUS Business School Doctor of Research in Management, Bina Nusantara University, Jakarta \\ Email:bahtiars@binus.edu \\ ${ }^{4}$ Management Department, BINUS Business School Doctor of Research in Management, Bina Nusantara University, Jakarta \\ Email: adler.manurung@binus.ac.id
}

\begin{abstract}
ABSTRAK
Era Industri 4.0 membawa Teknologi Informasi menjadi aset strategis bagi perusahaan dalam mengembangkan model bisnis inovatif dan dinamis. Namun sampai saat ini tingkat keberhasilan implementasi TI masih relatif rendah. Penelitian ini melakukan studi komparatif dengan membandingkan best practice dan faktor kesuksesan industri konstruksi dalam pembangunan gedung dengan implementasi TI. Dipilihnya industri arsitektur dan konstruksi bangunan sebagai pembanding, karena industri ini memiliki tingkat kemapanan dan tingkat keberhasilan implementasi yang cukup tinggi. Metode penelitian dilakukan dengan pendekatan Comparative Research, melalui studi literatur, wawancara (depth interview) dengan pelaku bisnis. Kemudian dilakukan Comparability Analysis dengan membandingkan best practice antara kegiatan operasional konstruksi dan implementasi TI. Informasi yang diperoleh diolah secara kualitatif untuk menghasilkan rekomendasi dan design guideline dalam mendesain solusi TI, agar tingkat keberhasilan implementasi TI lebih baik. Hasil analisa komparatif mengidentifikasikan 7 faktor penyebab tingkat keberhasilan yang baik pada industri konstruksi. Selain itu juga diidentifikasi 5 tantangan dan 4 kendala yang dihadapi industri TI, yang menghambat tingkat keberhasilan implementasi. Penelitian ini membandingkan pola kerja Arsitek-Kontraktor di industri konstruksi dengan Analyst-Developer pada industri TI. Lebih lanjut membahas sinerji dan hubungan antara AMO (Architecture Management Office) dan PMO (Project Management Office) dalam industri konstruksi dan industri TI. Sebagai kesimpulan penelitian, diidentifikasi tiga karakteristik design guideline untuk mendesain solusi TI, yaitu: Governance, Operation dan Growth. Penelitian eksploratif ini dapat dilanjutkan lebih dalam secara empirik untuk pengembangan design guideline perancangan solusi TI dengan industri terkait.
\end{abstract}

Kata Kunci: Arsitektur Bangunan; Arsitektur Teknologi Informasi; Studi Komparatif; Architecture Management Office, Project Management Office; Design Guideline.

\begin{abstract}
Industry 4.0 Era leads Information Technology to become a Strategic asset for companies to develop innovative and dynamic business models. Until recently the success rate of IT implementation is still relatively low. This research is a comparative study by comparing best practices and success factors in building construction industry with IT implementation. The construction industry was chosen as a comparison because this industry has a high level of reliability and successful implementation. The research method was conducted using the Comparative Research approach, through literature studies, depth interviews with subject matter expert. Then a Comparability Analysis is performed by comparing the best practices between construction operations and IT implementation. The information obtained is processed qualitatively to produce recommendations and design guidelines in designing IT solutions to improve success rate of IT implementation. The results of comparative analysis identify 7 factors that cause a good success rate in the construction industry. It also identified 5 challenges and 4 obstacles facing the IT industry, which hampered the success rate of implementation. This study compares the Architect-Contractor work patterns in the construction industry and Analyst-Developers in the IT industry. It further discusses the synergy and the relationship between AMO (Architecture Management Office) and PMO (Project Management Office) in the construction industry and IT industry. In conclusion, this study identified three characteristics of design guidelines for designing IT solutions, which is: Governance, Operation, and Growth. This explorative research can be continued by developing empiric research to develop design guidelines for designing IT solutions that uniqe in related industries.
\end{abstract}

Keywords: Building Architecture; Information Technology Architecture; Comparative Study; Architectural Management Office, Project Management Office; Design Guidelines. 


\section{PENDAHULUAN}

\section{Latar Belakang}

"To create architecture is to put in order. Put what in order? Function and objects." (Le Corbusier)

Mengutip pernyataan Le Corbusier diatas, ada tiga kata kunci untuk mendefinisikan arsitektur, yaitu susunan (order), fungsi (function) dan obyek (objects) (Harrouk, 2019). Le Cobusier bukan seorang pakar teknologi informasi, melainkan seorang arsitek bangunan, perencana kota, dan salah satu pelopor arsitektur modern. Namun apa yang dinyatakannya mengenai arsitektur bangunan serupa dengan yang dialami oleh pengembang solusi TI, yaitu menyusun fungsi dan obyek untuk membangun aplikasi. Lebih dalam lagi, membangun gedung tidak hanya dilihat sebagai pembangunan fisik yang disusun dari fungsi dan obyek material semata. Lebih dari itu bangunan dilihat sebagai aset yang memiliki nilai finansial dan ekonomis bagi pemilik dan investor. Dari perspektif yang sama pengembangan solusi Teknologi Informasi dapat dilihat sebagai pengembangan aset strategis yang memiliki nilai ekonomis.

Industri konstruksi bangunan, merupakan salah satu industri tertua di era modern. Industri ini memiliki dua bidang utama yang membentuknya, yaitu : bidang arsitektur dan sipil dengan konstruksi. Arsitektur dan sipil melakukan pekerjaan desain, rekayasa dan rancang bangun, maka konstruksi membangun gedung tersebut dengan mengelola sumber daya berdasarkan rancang bangun dari arsitek dan sipil. "Everything created twice", segala sesuatu diciptakan dua kali, merupakan ungkapan yang tepat untuk menggambarkan pekerjaan arsitektur dan konstruksi, yaitu pertama diranah abstraksi dan kedua dilingkup fisik (Ambler, 2010).

Industri konstruksi bangunan telah mencapai tingkat kemapanan dan maturitas yang tinggi. Membangun sebuah gedung melibatkan berbagai disiplin ilmu dengan tingkat kompleksitas yang tinggi (Hale, 2018). Beberapa informasi yang dikumpulkan dari narasumber di Quora (2019), secara umum dibutuhkan waktu 3 tahun untuk membangun gedung 30 lantai, dan 4 tahun untuk gedung 50 lantai. Bahkan sebuah gedung pencakar langit 57 lantai di Cina, dibangun hanya dalam waktu 19 hari. Kuncinya dengan menggunakan metode Modular Construction (Baer, 2015). Di sisi lain, Industri Teknologi Informasi mulai berkembang di paruh akhir abad ke-20. Berkembangnya teknologi mikroprosesor dan bahasa pemrograman mendorong proliferasi dan pemanfaatan teknologi informasi diberbagai segi kehidupan. Pemanfaatan Teknologi Informasi pada bidang bisnis dan industri semakin berkembang pesat, namun menghadapi tantangan dan akselerasi perubahan yang sangat cepat.

\section{Rumusan Masalah}

Di era Industri 4.0, IT merupakan aset strategis perusahaan dalam mengembangan model bisnis inovatif dan dinamis dalam menghadapi era disrupsi. Teknologi Informasi tidak lagi dilihat sebagai sarana pendukung namun menjadi daya ungkit dan aset strategis yang menghasilkan produk dan layanan inovatif bagi perusahaan. Namun investasi dalam membangun IT sebagai aset strategis perusahaan memiliki resiko yang tinggi. Perusahaan dihadapkan pada IT Dilema, dimana tingkat keberhasilan implementasi TI cukup rendah, berbanding nilai rata-rata investasi TI yang tinggi. Hal ini mengakibatkan inisiatif TI memiliki resiko kegagalan yang tinggi dan potensi inefisiensi besar.

Gambar 1 menunjukan kondisi aplikasi Enterprise System setelah 18 bulan dan 36 bulan sejak pembelian. Dari penelitian Gartner tersebut setelah 18 bulan, 25\% diimplementasikan, $25 \%$ sebagian diimplementasikan dan 50\% tidak diimplementasikan, gagal atau ditinggalkan. Setelah 
36 bulan terjadi peningkatan sistem yang diimplementasikan menjadi $30 \%$, terdapat penurunan sistem yang sebagian diimplementasikan menjadi $10 \%$. Namun sistem yang tidak diimplementasi, gagal atau ditinggalkan naik menjadi $60 \%$.

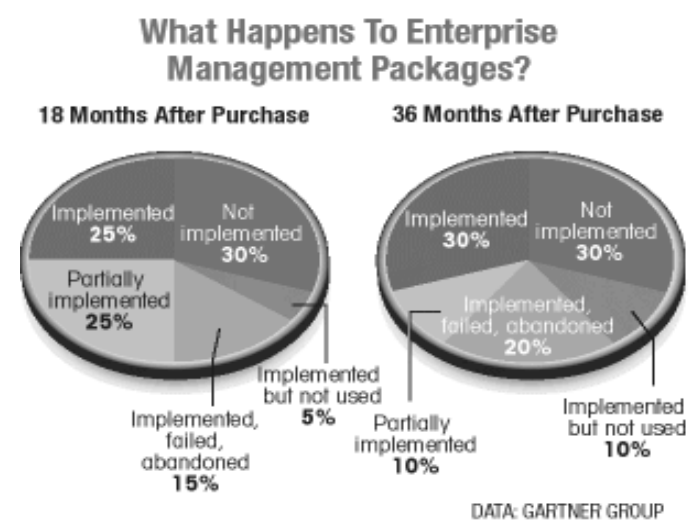

Gambar 1 Kondisi Sistem Aplikasi Setelah 18 dan 36 Bulan Pembelian

(Sumber: Gartner, 2012)

Hasil survey Dynamics Market dari CIO.com terhadap 800 Manajer TI, melaporkan bahwa $62 \%$ proyek TI gagal memenuhi jadwal. Kegagalan lain adalah $49 \%$ melebihi anggaran; $47 \%$ melebihi ekspektasi biaya pemeliharaan; $41 \%$ gagal memberikan nilai bisnis dan ROI yang diharapkan (Kabai, 2013; Mieritz, 2012). Biaya yang ditanggung dari kegagalan TI di seluruh dunia: \$3 trillion (Krigsman, 2012). Secara agregat pendapatan perusahaan Standard \& Poor 500 tahun 2012, diperkirakan mencapai \$10 triliun. Jika 5\% dari pendapatan tersebut dialokasikan ke investasi TI, bila secara konservatif $20 \%$ dari investasi tersebut gagal, maka berarti terjadi pemborosan sebesar $\$ 100$ milyar.

Industri TI dapat mempelajari best practice dari industri konstruksi bangunan dalam merancang dan membangun aset strategis yang memiliki nilai ekonomis bagi perusahaan. Sasaran dari penelitian ini adalah mempelajari faktor kesuksesan dari industri konstruksi bangunan untuk diterapkan kedalam industri teknologi informasi. Memahami praktek terbaik (best practice) yang dilakukan oleh pelaku industri konstruksi bangunan dan pelaku industri teknologi informasi. Hasil penelitian ini memberikan kontribusi dalam pengembangan metodologi analisis dan pengembangan solusi TI serta pengembangan design guideline dalam membangun aset teknologi agar diperoleh tingkat keberhasilan implementasi yang baik.

\section{METODE PENELITIAN}

Penelitian ini menggunakan metodologi comparability analysis, dengan melakukan studi komparatif antara best practice industri konstruksi dengan industri TI. Comparability analysis adalah metodologi penelitian dalam ilmu sosial, dimana dibandingkan dua obyek atau lebih, dengan maksud menemukan obyek-obyek yang dibandingkan. Metode ini dapat melibatkan berbagai disiplin ilmu dalam satu penelitian. Mayoritas peneliti sepakat bahwa tidak ada metodologi baku untuk penelitian komparatif (Caiden, Dierkes, Weiler, \& Antal, 1988). Comparability analysis melakukan penyelidikan terhadap dua atau lebih alternatif, proses, produk, kualifikasi, set data, sistem, dll secara berdampingan. Hasil penyelidikan tersebut diharapkan menghasilkan informasi bermakna yang menjelaskan kesetaraan, kesamaan atau dasar yang sama dari obyek penelitian. Tingkat komparabilitas yang sangat tinggi dapat mengindikasikan keseragaman. 
Dalam penelitian ini, data kualitatif dikumpulkan melalui wawancara mendalam (in-depth interviews) dengan pimpinan perusahaan dan dokumen dari perusahaan yang relevan digunakan dalam penelitian. Peneliti melakukan wawancara mendalam dengan beberapa pakar dan profesional perusahaan konstruksi dan TI nasional. Hasil wawancara dengan nara sumber dan studi literatur memaparkan faktor keberhasilan konstruksi bangunan dan meninjau penyebab kegagalan implementasi TI. Penelitian komparatif, dilakukan dengan melakukan studi literatur dari 12 paper dan 5 studi kasus. Komparasi best practice dari industri konstruksi dan industri TI, untuk membandingkan metode yang digunakan dalam konstruksi bangunan dan implementasi TI.

Selain itu dilakukan observasi ke site visit proyek konstruksi, di wilayah Jakarta dan Tangerang untuk memahami operasional pekerjaan konstruksi dilapangan. Lokasi penelitian dilakukan di kantor pusat perusahaan konstruksi. Peneliti menghadiri beberapa konferensi dan pameran industri konstruksi di Jakarta untuk berinteraksi dengan pelaku industri. Hal ini dilakukan untuk memahami lebih dalam fenomena perihal industri konstruksi dan implementasi TI di perusahaan.

\section{HASIL DAN PEMBAHASAN}

\section{Belajar Dari Industri Konstruksi}

Dalam membangun suatu gedung banyak sekali pihak yang terlibat dari berbagai disiplin ilmu, antara lain: pertanahan, struktur, kelistrikan, air, desain dan berbagai bidang lain yang perlu berkoordinasi satu dengan yang lainnya menjadi satu kesatuan. Kompleksitas dan resiko dalam pekerjaan membangun gedung sangat tinggi sehingga perlu regulasi yang ketat dan standar keamanan yang baik. Secara umum tingkat keberhasilan membangun gedung lebih besar dari pada pengembangan solusi TI di perusahaan. Ada beberapa sebab yang menjelaskan fenomena ini dari hasil wawancara dan literature review (GAMBATESE \& HALLOWELL, 2011; Norizam \& Malek, 2013; Shen et al., 2010), yaitu :

a. Industri konstruksi bangunan merupakan industri dengan umur panjang dengan basis pengetahuan kolektif yang besar. Collective Knowledge industri konstruksi telah memiliki rentang yang sangat panjang, bahkan sejak jaman abad pertengahan, ketika setiap kerajaan di Eropa berlomba membangun katedral dengan menara tertinggi. Sebaliknya industri TI masih relatif pendek, belum mencapai 50 tahun sejak komputer Apple pertama dipasarkan oleh Steve Jobs. Namun dengan berkembangnya ilmu pengetahuan, industri TI dapat menyusul menuju kemapanan. Hal ini dapat dicapai dengan mengadopsi best practice dari industri yang telah mapan.

b. Industri konstruksi bangunan, memiliki basis tenaga kerja yang besar. Lulusan jurusan arsitektur dan teknik sipil di Indonesia setiap tahun berjumlah puluhan ribu. Lulusan jurusan Teknologi informasi di Indonesia semakin meningkat, namun masih belum menyamai jumlah lulusan arsitektur dan teknik sipil. Bila suatu industri memiliki jumlah tenaga kerja yang besar, maka akan memberikan stabilitas biaya tenaga kerja dan memudahkan industri untuk mencari tenaga kerja. Hal ini akan mempercepat perusahaan mengadopsi industri tersebut.

c. Asosiasi Industri, yang sudah lama dan berpengaruh. Asosiasi industri membangun basis komunitas yang kuat dalam sebuah industri. Keberadaan sebuah asosiasi menandakan bahwa industri tersebut telah memiliki skala yang signifikan bagi pertumbuhan industri nasional. Amerika memiliki asosiasi profesi Arsitek, The American Institute of Architects (AIA) yang sudah berumur puluhan tahun. Indonesia memiliki asosiasi arsitek, Ikatan Arsitek Indonesia (IAI). Industri TI sudah memiliki asosiasi arsitek TI internasional, Internation Association of Software Architect (IASA). Namun umur IASA masih relatif muda sekitar 8 tahun. Indonesia memiliki asosiasi industri TI, seperti Asosiasi Piranti Lunak Telematika Indonesia. Bila 
dibandingkan kedua industri tersebut, maka asosiasi industri konstruksi memiliki asosiasi yang sudah berumur panjang dengan basis yang besar.

d. Industri konstruksi memiliki basis pengetahuan (body of knowledge) yang besar dengan tingkat maturitas tinggi. Industri konstruksi bangunan memiliki akumulasi pengetahuan yang luas dan mulai terintegrasi. Sedangkan Bidang TI masih terus berkembangan secara dinamis dan berubah dengan cepat. Basis pengetahuan yang terus berkembangan secara dinamis.

e. Standarisasi pekerjaan yang sudah baku dan diterima secara global. Standarisasi adalah salah satu syarat untuk mencapai efisiensi. Industri konstruksi bangunan sudah mencapai tahap standarisasi yang mapan. Industri TI masih bergerak secara dinamis, perubahan sangat cepat terjadi membuat standarisasi industri masih menjadi tantangan bagi para pelaku industri. Standarisasi yang ada di industri TI ditangani oleh konsorsium, antara lain Object Management Group (OMG). Standarisasi di industri TI antara lain dengan penerapan Pemrograman berbasis Obyek (Object Oriented Programming) dan Cloud Computing.

f. Metode pekerjaan dengan menggunakan Prefabrikasi untuk meningkatkan efisiensi dan komunikasi. Prefabrikasi, merupakan kata kunci pada industri konstruksi bangunan. Desain dan konstruksi bangunan modern dikembangkan dengan metode modular dan prefab (Smith, 2011). Peran arsitek dan desainer akan semakin besar, karena sebelum bangunan dikerjakan seluruh komponen harus sudah 'jadi' dimeja gambar. Industri TI juga sudah mencoba menerapkan konsep pre-fabrikasi dalam pengembangan aplikasi. Hal ini kita kenal dengan konsep Object Oriented Programming. Pendekatan ini hampir sama dengan penerapan prefabrikasi, terutama untuk reusability.

g. Pertumbuhan industri relatif stabil dan mapan. Kebutuhan akan tempat tinggal merupakan kebutuhan utama manusia. Sehingga selama manusia berbudaya masih ada, maka kebutuhan akan rumah dan bangunan akan selalu berkembang. Dilain sisi, industri TI yang masih relatif muda, namun perannya semakin besar pada kehidupan manusia. Sebagai contoh industri telekomunikasi yang bergerak menjadi kebutuhan primer. Saat ini penetrasi telepon selular sudah merambah pedesaan, tidak lagi menjadi milik orang kota. Investasi infrastruktur komunikasi yang menjadi pondasi industri TI juga sudah semakin meluas. Teknologi Informasi juga sudah merambah budaya terutama bagi generasi millenial.

Dari pembahasan ketujuh faktor diatas dapat dilihat bahwa industri TI memiliki pola arah maturitas industri yang selaras dengan faktor-faktor yang membentuk industri konstruksi bangunan. Namun Industri TI ditengah umurnya yang masih relatif muda, masih memerlukan waktu untuk menuju ke kondisi matang.

\section{Penyebab Kegagalan Implementasi Teknologi Informasi}

Menghadapi era digital, teknologi informasi menjadi aset strategis bagi perusahaan. Investasi TI menjadi investasi strategis dalam membangun kapabilitas perusahaan. Dengan meningkatkan keberhasilan TI dan akurasi implementasi TI maka diharapkan dapat menurunkan biaya investasi, mengurangi resiko dan memberikan keyakinan kepada pengguna. Namun ada beberapa kendala dalam penerapan TI pada perusahaan khususnya perusahaan di Indonesia. Informasi diperoleh dari hasil wawancara dengan beberapa eksekutif dan manajer bidang TI di berbagai perusahaan nasional.

a. Tantangan 1 : Posisi TI yang masih dipandang sebagai support dan belum dapat dilihat bernilai strategis. Hal ini dikarenakan ekosistem ekonomi indonesia porsi besar ada pada perusahaan konvensional, seperti manufaktur, perdagangan, pertambangan dan hasil bumi. Hal ini dapat dilihat dari posisi struktur organisasi fungsi TI, yang masih berada dibawah General Affair atau 
Finance. Fungsi TI masih terbatas sebagai dukungan layanan pengembangan aplikasi dan infrastruktur, seperti internet, komunikasi, dan e-mail. Saat ini industri perbankan adalah yang terdepan dalam melihat TI sebagai aset strategis yang perlu dikelola dengan baik.

b. Tantangan 2 : IT Literacy dan Awareness dari mayoritas pengguna TI di perusahaan masih rendah. Tidak jarang perusahaan sudah menerapkan sistem TI yang mahal, namun pada akhirnya tidak digunakan karena tidak dimanfaatkan oleh pengguna. Pengguna tidak mau berubah dan kembali ke pola pekerjaan lama. Implementasi TI memerlukan manajemen perubahan.

c. Tantangan 3 : Implementasi TI berdampak pada perubahan budaya kerja, dan memerlukan perubahan. Adanya TI dapat membawa perubahan pola kerja dan budaya baru, yang sering tidak siap dihadapi oleh pengguna. Merubah pola kerja seseorang yang sudah terbiasa dengan kebiasaan lama. Perlunya aspek komunikasi, pembelajaran dan motivasi serta manajemen perubahan yang didukung manajemen puncak.

d. Tantangan 4 : Anggapan bahwa TI adalah solusi untuk semua masalah yang dihadapi oleh perusahaan. Implementasi TI perlu dukungan semua lapisan organisasi agar dapat tercapai tujuan strategisnya. Sebagai aset strategis perusahaan, maka TI merupakan milik seluruh organisasi dalam menjalankan tujuan bisnisnya. Bagian bisnis perlu memahami wawasan TI untuk memanfaatkan potensi dan menggunakan kapabilitasnya. Bagian TI memerlukan wawasan bisnis untuk dapat mengembangkan investasi TI secara strategis dalam mencapai tujuan bisnis organisasi.

e. Tantangan 5 : Implementasi TI di perusahaan Indonesia masih vendor-driven. Kurangnya alternatif pilihan perusahaan terhadap sistem integrator dan profesional bidang TI yang bisa memberikan solusi sesuai dengan kebutuhan perusahaan. Saat ini hampir semua perusahaan masih bertindak sebagai box mover dari vendor-vendor besar. Perusahaan tidak mempunyai banyak pilihan dan kadang menerima apa yang sudah dipaketkan oleh vendor. Dengan biaya yang tinggi dan solusi yang tidak efisien dan sesuai dengan kebutuhan.

Kelima tantangan diatas berasal dari dorongan eksternal dan internal organisasi, serta kondisi lingkungan bisnis di Indonesia. Dari tantangan, maka diidentifikasi beberapa kendala terkait implementasi solusi TI. Kendala merupakan hambatan yang dibawa dari internal Teknologi Informasi itu sendiri.

a. Kendala 1 : Solusi TI menghasilkan produk non-fisik. Berbeda dengan arsitektur gedung yang menghasilkan bentuk fisik, maka produk TI tidak memiliki bentuk fisik yang dapat dilihat atau dirasakan secara langsung. Sehingga melakukan valuasi atau menilai produk TI lebih sulit dibandingkan dengan aristektur bangunan. Demikian juga untuk menjabarkan faktor kesuksesan atau tingkat keberhasilan dari solusi TI.

b. Kendala 2 : TI merupakan platform teknologi. Artinya TI menjadi fondasi baik infrastruktur dan aplikasi dimana proses bisnis secara umum berjalan diatasnya. Sebagai contoh dalam proses manufaktur, aplikasi MRP dan ERP yang dikelola TI akan menjadi platform untuk menggerakan strategi Continuous Improvement atau Process Reengineering dari bisnis. IT berperan sebagai Strategic Leverage bagi organisasi dalam mencapai tujuan bisnisnya.

c. Kendala 3 : Kompleksitas yang tinggi. TI memiliki komponen, obyek dan fungsi yang saling berhubungan, sehingga dalam menyusun desain arsitekturnya ada banyak aspek yang perlu dipertimbangkan. Obyek dan fungsi yang saling berkaitan meningkatkan kompleksitas perancangan dan pengembangan TI. Industri konstruksi bangunan juga memiliki kompleksitas yang tinggi dan melibatkan beberapa disiplin ilmu yang berbeda.

d. Kendala 4 : Kecenderungan fragmentasi. Secara umum pengembangan TI di dalam organisasi masih terbangun silo. Walau dewasa ni sudah terbangun kesadaran perlunya menghapus pagar dan silo yang terbangun, dalam implementasinya tidak mudah. Pendekatan Enterprise 
Architecture merupakan satu metodologi untuk meningkatkan integrasi dan koordinasi investasi TI (Ross, 2006; Van Steenbergen \& Brinkkemper, 2009). Seperti layaknya kontruksi gedung yang dibangun dalam satu orkestrasi dan bersinerji. Kurangnya integrasi arsitektur TI dalam organisasi mengakibatkan perkembangan TI terkotak-kotak sesuai kebutuhan masingmasing fungsi di dalam organisasi. Bagian berikut membandingkan mengenai metode pekerjaan konstruksi bangunan dengan implementasi TI.

\section{Membandingkan Metode Konstruksi Bangunan dengan Metode Implementasi TI}

Metodologi pekerjaan konstruksi bangunan mencakup aspek yang luas dengan kompleksitas yang cukup tinggi. Demikian pula dengan metodologi implementasi TI, baik berupa pengembangan aplikasi, integrasi sistem atau instalasi infrastruktur, memiliki aspek yang luas dan beragam. Untuk memahami perbedaan kedua industri tersebut dilakuan tinjauan komparatif analisis terhadap best practice dan metodologi pekerjaan.

Dari perbandingan tersebut dapat ditarik kesimpulan, bahwa industri konstruksi bangunan memiliki pembagian pekerjaan dengan sinerji secara jelas antara kegiatan Arsitektur (desain) dan Konstruksi (pembangunan fisik) (Boyd, 2012). Sedangkan industri TI belum secara spesifik memiliki pembagian pekerjaan antara tahapan analisis (desain) dan pengembangan (programming/coding).

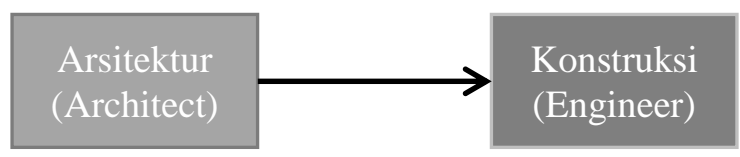

Gambar 2 Pembagian kerja yang jelas antara Arsitektur dan Konstruksi

Sumber: Penulis, 2019

Dalam industri konstruksi bangunan sangat jelas pembagian peran dan sinerji antara keahlian arsitek dan engineer. Satu pihak yang merancang satu pihak yang membangun, masing-masing fokus pada keahlian dan job skill-nya namun tetap terjadi sinerji sehingga diperoleh rancang bangun yang benar-benar baik. Sebuah gedung dapat direncanakan lebih dari satu arsitek, sehingga pemilik bangunan lebih luas dapat memilih mana yang terbaik. Pembagian pekerjaan atau division of work and expertise ini memberikan ruang yang lebih luas untuk inovasi, kreativitas dan pilihan. Keterlibatan pemilik gedung dalam menentukan desain menjadi salah satu faktor kunci kepuasan dan keberhasilan pembangunan sebuah gedung.

\section{Design \\ Development \\ (Analyst) (Programer)}

Gambar 3 Pembagian Pekerjaan yang Perlu Diperjelas Antara Analis dan Programer

Sumber: Penulis, 2019

Disisi lain, pelaku industri TI, umumnya di Indonesia, belum memiliki peran yang jelas antara analis dan programer. Seringkali peran analis dikerjakan oleh programmer yang belum memiliki keahlian desain dan perancanaan. Sehingga sistem aplikasi yang dikembangkan secara subyektif berasal dari perspektif programer, dibandingkan dari kebutuhan pengguna. Hal ini mengakibatkan dalam perjalanannya sistem TI yang dikembangkan bersifat parsial dan bertumbuh secara firefighting, perubahan atau desain dilakukan bila dibutuhkan. 
Dalam mengembangkan desain salah satu faktor yang menjadi pertimbangkan utama adalah memproyeksikan kebutuhan kedepan dan perencanaan kapasitas (capacity planning). Hal ini yang umumnya tidak didapat ketika analis atau desainer tidak dilibatkan secara benar pada pekerjaan. Penelitian ini mengusulkan perlunya memperluas peran analis sebagai arsitek yang membangun aset teknologi perusahaan. Bersinerji bersama-sama dengan developer yang menaungi programmer, system integrator dan infrastructure engineer.

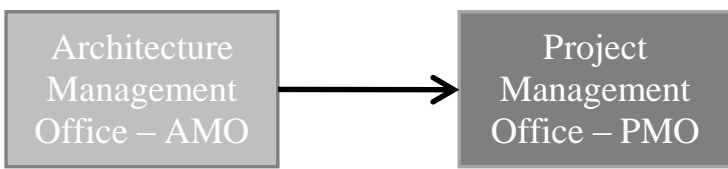

Gambar 4 Sinerji AMO dan PMO

Sumber: Penulis, 2019

Gambar diatas menunjukan peran Arsitek TI yang berada dalam lingkup Architecture Management Office (AMO), sebuah fungsi organisasi yang bertugas untuk (Cuenca, Boza, \& Ortiz, 2011; Lange, Mendling, \& Recker, 2011; Sousa, Lima, Sampaio, \& Pereira, 2009) :

a. Mengelola investasi strategis berupa aset teknologi informasi berdasarkan kebutuhan bisnis dan digunakan untuk mencapai tujuan organisasi.

b. Merancang sistem TI sesuai dengan kebutuhan Organisasi

c. Menjaga dan mengelola Aset Intelektual Organisasi. Berupa proses bisnis, diagram, kajian dan laporan

d. Menguasai notasi pemetaan dan penggambaran yang baku, dalam mendesain sistem. Seperti Flowchart, UML, BPMN dan sebagainya.

e. Menjaga dan memelihara hasil analisa dan rancangan sistem organisasi, serta menyesuaikan dengan kebutuhan perusahaan secara berkesinambungan.

f. Test, Measure and Improve dari sistem yang ada saat ini. Bertindak sebagai quality assurance dan memastikan sistem yang dibangun sesuai dengan kebutuhan yang direncanakan.

AMO bekerjasama secara sinerji dengan Project Management Office (PMO). Hasil rancangan dari AMO akan dikerjakan dan dibangun oleh PMO. PMO terdiri dari para Project Manager, Vendor Relation, Developer, Programmer dan System Integrator. Tugas PMO adalah sebagai berikut (Bryde, Broquetas, \& Volm, 2013; Rokooei, 2015):

a. Membangun sistem berdasarkan rancangan dari AMO.

b. Membangun sistem TI dengan metode pengembangan yang baik. Seperti SDLC, Scrum, Spiral, Extreme Programming, Dsb.

c. Melakukan rencana pengembangan kapasitas dan pengembangan infrastruktur.

d. Memberi masukan secara berkesinambungan kepada AMO mengenai perkembangan teknologi dan kesisteman yang ada.

Sinerji antara AMO dan PMO ini diharapkan dapat menjadi salah satu faktor untuk meningkatkan keberhasilan implementasi TI dalam organisasi. AMO menjadi sinerji atau alignment center antara inisiatif strategis bersama Bisnis dan Teknologi. Penamaan AMO tidaklah mutlak, bisa saja fungsi perencanaan yang sudah ada dikembangkan meliputi deskripsi pekerjaan dan tanggung jawab AMO tanpa perlu merubah nama. Sebagai contoh di beberapa bank AMO bernama Transformation Office. Secara umum PMO banyak diterapkan pada perusahaan dalam mengelola proyek dan inisiatif TI untuk memilih vendor dan lelang. 


\section{KESIMPULAN DAN SARAN}

\section{Karakteristik Implementasi TI}

Penelitian untuk meningkatkan keberhasilan implementasi TI cukup banyak ditemukan. Namun sebagian besar masih dilakukan secara internal, atau dalam konteks di dalam industri TI. Penelitian ini melakukan studi komparasi dengan industri yang sudah establish, yaitu membandingkan dengan konstruksi bangunan. Salah satu pola yang ditemukan adalah diperlukannya design guideline yang sesuai dengan karakteristik gedung yang akan dibangun. Seorang arsitek dalam membangun gedung biasanya harus memahami terlebih dahulu karakter dari calon penghuninya. Juga melakukan analisa kebutuhan ruang dan peruntukan bangunan. Kebutuhan tiap bangunan adalah unik. Sebagai contoh, gedung rumah sakit, gedung perkantoran, dan pusat perbelanjaan masing-masing memiliki karakter dan peruntukan yang berbeda. Karena itu setiap jenis gedung memiliki design guideline-nya sendiri.

Melihat best practice dalam membangun design guideline, maka dalam implementasi TI perlu dilakukan kajian terhadap karakteristik industri dan ekosistem dimana perusahaan ini berada. Setiap industri perlu mengembangkan design guideline aristektur TI nya sendiri. Karena setiap industri memiliki karakter dan kebutuhan terhadap TI yang berbeda dan unik. Dari hasil penelitian kualititatif yang dilakukan, maka diperoleh 3 kelompok karakter dari perusahaan yang membutuhkan implementasi TI. Dari Ketiga karakter tersebut diturunkan beberapa elemen sifat yang membentuk karakter tersebut. Gambar 6 menunjukan ketiga karakter tersebut.

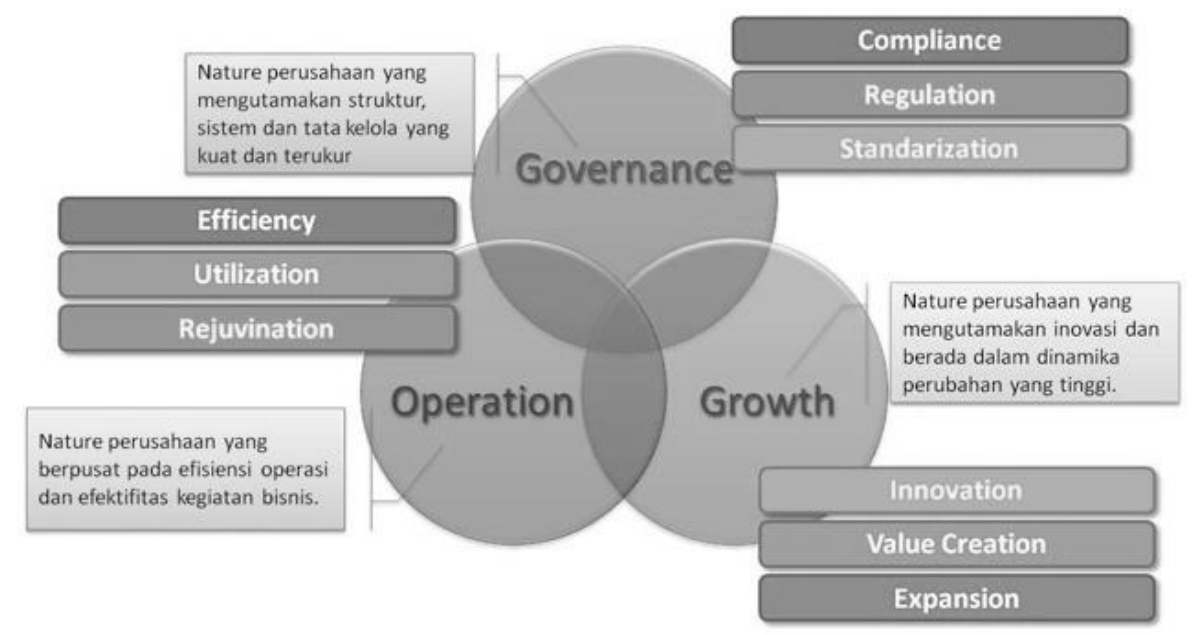

Gambar 5 Karakteristik Implementasi IT

Sumber: Penulis, 2019

Karakter 1 : Governance atau Tata Kelola. Disini implementasi diutamakan untuk mendukung tata kelola, kepatutan dan kepatuhan terhadap sistem. Dalam karakter ini penerapan TI harus memiliki standarisasi yang dilengkapi sertifikasi dari nasional maupun internasional. Perusahaan atau organisasi yang masuk dalam karakter ini biasanya perusahaan perbankan atau institusi pemerintah.

Contoh implementasi TI dari karakter ini adalah penerapan COBIT dan IT Audit diperusahaan. Selain itu kegiatan Business Process Automation, IT Service Management, Security dan Business Continuity, juga termasuk dalam karakter tata kelola. Karakter ini memiliki 3 sasaran sifat, yaitu:

a. Compliance : Mengenai bagaimana implementasi TI sesuai dengan Best Practice yang dimiliki oleh industri dan asosiasi.

b. Regulation : Mengenai bagaimana implementasi TI sesuai dengan peraturan dan kebijakan perusahaan, dan atau peraturan yang ditetapkan pemerintah terhadap satu industri. 
c. Standarization : Mengenai bagaimana impelmentasi TI dapat mendukung standarisasi pekerjaan dan mendukung operasional sistem yang baku. Hal ini dimaksudkan agar tercapai efisiensi dan menghilangkan ketergantungan dari faktor manusia dan lebih mengutamakan sistem.

Karakter 2 : Operation. Dalam karakter ini, implementasi TI diutamakan untuk mendukung operasional perusahaan agar efektif dan efisien. Perusahaan yang memiliki karakter ini adalah perusahaan manufaktur dan perdagangan.

Contoh implementasi TI dari karakter ini berupa penerapan SAP, ERP, CRM atau HRM. Karakter ini memiliki 3 sasaran sifat, yaitu :

a. Efficiency : Bagaimana implementasi dapat mendukung efisiensi perusahaan. Menghemat biaya, mempercepat produksi dan memperbesar kapasitas.

b. Utilization : Bagaimana implementasi TI mendukung peningkatkan utilisasi atau penggunaan aset-aset perusahaan. Sehingga optimal dan menghasilkan return yang lebih baik.

c. Rejuvination : Bagaimana implementasi TI dapat mendukung peremajaan alat-alat produksi yang sudah lama dan dapat meningkatkan kinerja dan performa organisasi.

Karakter 3 : Growth. Implementasi TI mengarah kepada pengembangan bisnis. Pada karakter ini TI tidak dipandang lagi sebagai support namun aset strategis perusahaan dalam mengembangankan bisnis perusahaan. Umumnya perusahaan yang memiliki karakter ini adalah perusahaan TI dan Telekomunikasi atau perusahaan berbasis teknologi. IT is the business itself. Sebagai contoh implementasi dari karakter ini adalah penerapan Online Market Place, atau Mobile Payment System. Di era unicorn saat ini, penerapan design guideline ini sesuai untuk perusahaan startup.

a. Innovation : Bagaimana implementasi TI mendukung inovasi model bisnis dan memperluas pangsa pasar perusahaan dengan menggapai pelanggan baru. Blue Ocean Strategy. Perusahaan teknologi tinggi seperti Apple, Google dan Facebook yang sangat kental dengan inovasi dalam strategi bisnis mereka.

b. Value Creation : Menciptakan rantai Nilai baru yang mengubah landscape bisnis industri pola lama. Seperti Air Asia atau Fed Dex.

c. Expansion : Bagaimana implementasi TI mendukung ekspansi dan perluasan perusahaan. Baik kapasitas produksi dan perluasan pangsa pasar. Sebagai contoh yang dilakukan BCA dengan implementasi KlikBCA.

Arsitek TI perlu melakukan peninjauan design guideline dari ketiga karakter diatas, untuk merancang TI yang sesuai kebutuhan industri. Setelah rancangan diperoleh baru kemudian dilakukan pengembangan dan implementasi TI. Bila implementasi TI dilakukan tanpa melihat karakteristik dan design guideline dari kebutuhan tiap industri, setiap perusahaan akan memiliki sistem yang serupa. Bagaikan sepanjang jalan Sudirman Thamrin semua gedung memiliki bentuk, gaya dan warna yang sama. Tidak memiliki keunikaan, seni dan variasi desain yang khas sesuai dengan karakter pemiliknya. Ini adalah dampak kurangnya pendekatan desain arsitektur, kecenderungan menggunakan framework yang sama untuk semua solusi TI di lintas industri.

Penelitian ini masih perlu dikembangkan lebih lanjut. Perlu adanya usaha terus menerus untuk mencari jawaban dan solusi terhadap tantangan industri TI nasional. Terutama dalam mengurangi faktor resiko dan meningkatkan tingkat keberhasilan implementasi. Penelitian komparatif ini bersifat eksploratif dan menjadi bahan penelitian selanjutnya yang lebih dalam dan empirik. Berikut ini adalah lima pertanyaan yang ditemukan dalam penelitian ini dan dapat menjadi dasar untuk penelitian selanjutnya.

a. Apakah semakin banyaknya komponen yang digunakan dalam satu pekerjaan, akan semakin meningkat kerumitannya? 
b. Bagaimana peran pola desain (design pattern), membantu meningkatkan keberhasilan, kecepatan dan akurasi implementasi TI?

c. Teknologi Informasi merupakan platform teknologi. Maknanya teknologi informasi merupakan enabler dan differentiator yang dapat meningkatkan kapasitas, kecepatan dan akurasi kegiatan bisnis. Bagaimana peran TI sebagai platform teknologi dengan kompleksitas implementasi TI?

d. Bagaimana alignment antara bisnis dan TI, serta sejauh mana hubungan keselarasan tersebut berpengaruh terhadap keberhasilan implementasi TI?

e. Apa saja Best Practice pada industri Arsitektur dan Konstruksi bangunan, yang dapat membantu mempercepat pengembangan dan implementasi TI?

Kelima pertanyaan diatas diharapkan dapat menjadi dasar pertimbangan dan diskusi dalam melakukan penelitian lebih lanjut. Dari penelitian ini dapat disimpulkan bahwa setiap industri perlu mempertimbangkan untuk mengembangkan design guideline yang menjadi panduan perusahaan dalam mengembangkan aset teknologi informasi mereka. Karakteristik Governance, Operation dan Growth menjadi dasar dalam merancang aset teknologi informasi untuk perusahaan.

\section{REFERENSI}

Ambler, S. W. (2010). Enterprise Architecture: Reality over Rhetoric. Retrieved March 24, 2015, from http://www.drdobbs.com/architecture-and-design/enterprise-architecture-reality-overrhe/224600174

Baer, D. (2015). A simple design innovation let a Chinese entrepreneur build a 57-story skyscraper in 19 days. Retrieved from https://www.businessinsider.com/chinese-skyscraperbuilt-in-19-days-with-modular-design-2015-6? IR=T

Boyd, D. (2012). The Architecture of Information: Architecture, Interaction Design and the Patterning of Digital Information. Construction Management and Economics. https://doi.org/10.1080/01446193.2012.656134

Bryde, D., Broquetas, M., \& Volm, J. M. (2013). The project benefits of building information modelling (BIM). https://doi.org/10.1016/j.ijproman.2012.12.001

Caiden, N., Dierkes, M., Weiler, H. N., \& Antal, A. B. (1988). Comparative Policy Research: Learning from Experience. Public Administration Review. https://doi.org/10.2307/976910

Cuenca, L., Boza, A., \& Ortiz, A. (2011). Architecting business and IS/IT strategic alignment for extended enterprises. Studies in Informatics and Control, 20(1), 7-18. Retrieved from http://www.sic.ici.ro/sic2011_1/art01.pdf

GAMBATESE, J. A., \& HALLOWELL, M. (2011). Factors that influence the development and diffusion of technical innovations in the construction industry. Construction Management \& Economics. https://doi.org/10.1080/01446193.2011.570355

Hale, K. (2018). Complex Project Management-What it is, and What Success Looks Like. Retrieved from https://www.business2community.com/strategy/complex-projectmanagement-what-it-is-and-what-success-looks-like-02107747

Harrouk, C. (2019). The Creative Process of the Four Pioneers of Modern Architecture. Retrieved from https://www.archdaily.com/925464/the-creative-process-of-the-fourpioneers-of-modern-architecture

Kabai, I. (2013). 8 Reasons Enterprise Architecture Programs Fail -. Retrieved March 24, 2015, from http://www.informationweek.com/global-cio/interviews/8-reasons-enterprisearchitecture-progra/240151679 
Krigsman, M. (2012). Worldwide cost of IT failure ( revisited ): \$ 3 trillion. Retrieved March 17, 2013, from http://www.zdnet.com/blog/projectfailures/worldwide-cost-of-it-failurerevisited-3-trillion/15424

Lange, M., Mendling, J., \& Recker, J. (2011). A comprehensive EA benefit realization model An exploratory study. In Proceedings of the Annual Hawaii International Conference on System Sciences (pp. 4230-4239). https://doi.org/10.1109/HICSS.2012.50

Mieritz, L. (2012). Gartner Survey Shows Why Projects Fail. Retrieved May 5, 2015, from https://thisiswhatgoodlookslike.com/2012/06/10/gartner-survey-shows-why-projects-fail/

Norizam, A., \& Malek, M. A. (2013). Developing critical success factors (CSFs) for effective construction management in Malaysia industry. Asian Social Science, 9(9), 211-218. https://doi.org/10.5539/ass.v9n9p211

Rokooei, S. (2015). Building Information Modeling in Project Management: Necessities, Challenges and Outcomes. Procedia - Social and Behavioral Sciences, 210, 87-95. https://doi.org/10.1016/j.sbspro.2015.11.332

Ross, J. W. (2006). Enterprise Architecture: Driving Business Benefits. Center for Information Systems Research, 259, 15. https://doi.org/10.2139/ssrn.920666

Shen, W., Hao, Q., Mak, H., Neelamkavil, J., Xie, H., Dickinson, J., ... Xue, H. (2010). Systems integration and collaboration in architecture, engineering, construction, and facilities management: A review. Adv. Eng. Inform., 24(2), 196-207. https://doi.org/10.1016/j.aei.2009.09.001

Smith, R. E. (2011). Prefab Architecture: A Guide to Modular Design and Construction. Architecture. John Wiley and Sons. Retrieved from http://books.google.com/books?hl=en\&amp;lr=\&amp;id=pOCliGMKpzUC\&amp;oi=fnd\&a mp;pg=PT20\&amp;dq=PREFAB+ARCHITECTURE:+a+guide+to+modular+design+and+ construction\&amp;ots=j0n5GteYZ6\&amp;sig=wUYE0qhNDvy5tN_r6P9WQe79p4U

Sousa, P., Lima, J., Sampaio, A., \& Pereira, C. (2009). An approach for creating and managing enterprise blueprints: A case for IT blueprints. In Lecture Notes in Business Information Processing (Vol. 34 LNBIP, pp. 70-84). https://doi.org/10.1007/978-3-642-01915-9_6

Van Steenbergen, M., \& Brinkkemper, S. (2009). The architectural dilemma: Division of work versus knowledge integration. CEUR Workshop Proceedings, 456. Retrieved from http://www.dya.info/sites/dya.info/files/attachments/Paper The architectural dilemma division of work vs knowledge integration door Marlies van Steenbergen en Sjaak Brinkkemper juni 2009.pdf 